\title{
Water, sustainability and poetics in the works of the cAt group
}

\author{
Keywords \\ Sustainability, Water, cAt group, Art-Technology
}

Since 2015, the cAt (science, Art, technology) research group from the Arts Institute of UNESP (São Paulo State University) has reflected upon Art-technology productions, that raise concerns about sustainability related to energy sources and alternative possibilities for energy generation without the direct use of computers and complex technology apparatus, while maintaining relevant aspects of the digital interactive works, such as the use of technology, interaction with the audience and a systemic view. These concerns were initially introduced in the production of the work "Sopro" ("Blow"), started in 2015, which is an interactive work powered by the audience participation through the strength of a wind blow on a pinwheel. This work is based on the use of a simple technological system, seeking the poetic dimension of the act of blowing and primary scientific principles. Upon the development of this work, the group sought the possibility of creating a series of works focused on concerns about sustainability with original interaction dynamics, thus creating new systems and works in which the body of the audience becomes the power source. In this context, not only the resulting works are important, but especially the creative process, in which artists focus their concerns and researches on socio-environmental issues, thus assuming a new view of the world, seeking new attitudes, new relationships with individuals and communities involved within this process, transforming their ways of life and materializing that into Art.In this paper we present the works that are part of the triptych, with each of the works having a different aspect, but related to the others. The works are presented in spherical, cubic and cylindrical formats. The public's physical relationship with the work takes place through a bodily activity, being blowing, touching and moving a part of the piece. The water is always present, but in a different physical state in each one, being part of the technological system and the poetic construction.In this article we focus on the water element, although other technological and symbolic aspects are present in the works. In the work "Sopro", in the liquid state, water represents the context in which life arises. In the second work, "Toque", in solid state, water serves as part of the technological process, in partnership with human contact, with the hot and cold contrast for energy generation. And in the third work, "Gesture", water represents the symbolic part of the work, related to the passage of water from a liquid to a gaseous state, such as the condensation that occurs in the rain process. 